\title{
PENTOXIFYLLINE: A THERAPEUTIC REMEDY FOR OPTIC NEUROPATHIES
}

Perwez Khan, Lubna Khan, Upma Awasthi, Abadan Khan, Zia Siddique, Ramesh Chand.
1. Assistant Professor Department. of Ophthalmology, GSVM Medical College Kanpur
2. Assistant Professor Department. of Pathology, GSVM Medical College Kanpur
3. Junior Resident Department. of Ophthalmology, GSVM Medical College
4. Professor Department. of Ophthalmology, J N Medical College AMU Aligarh
5. Lecturer Department. of Ophthalmology, J N Medical College AMU Aligarh
6. Associate Professor Department. of Ophthalmology, GSVM Medical College

\author{
CORRESPONDING AUTHOR: \\ Dr. Perwez Khan. \\ Assistant Professor, \\ Department of Ophthalmology \\ GSVM Medical College, Kanpur, UP, India. \\ E-mail: perwezkhan@gmail.com
}

\begin{abstract}
PURPOSE: To evaluate effect of oral pentoxifylline in optic neuropathies of different etiologies. METHOD: Thirty two patients (42 eyes) with different stages of optic atrophy of less than 1 year duration were selected for the study. They were randomly divided into two groups. Treatment group was given oral pentoxifylline $16-18 \mathrm{mg} / \mathrm{kg}$ body weight administered in two equal divided doses. Patients in Control group were kept on placebo for minimum of 6 months. Best corrected visual acuity (BCVA) was recorded at one, three and 6 months using Snellen's visual acuity charts. RESULTS: All patients completed minimum 6 month of treatment. In Treatment group, 03 eyes had pre-treatment visual acuity of light perception (PL), which at the end of 6 months of treatment attained BCVA of 20/80, 20/200, and finger counting at 2 feet respectively. Another 4 eyes in the treatment group had pre-treatment BCVA of no light perception (NPL) which showed no improvement after 6 months of therapy.

In control group 7 eyes with PL or NPL showed no improvement. Among rest of the patients, in treatment group pre-treatment and 6 month post-treatment median BCVA were $1.35 \pm 0.44$ and $0.75 \pm 0.45$ respectively ( $\mathrm{p}=0.002, \mathrm{CI}=-0.9$ to -0.25 ), while in control group, pre-treatment and post treatment median BCVA was $1.32 \pm 0.42$ and $1.31 \pm 0.42$ respectively $(\mathrm{p}=0.157, \mathrm{CI}=-0.5$ to 0.0 ), respectively.
\end{abstract}

CONCLUSION: Oral Pentoxifylline causes functional improvement as suggested by improved BCVA, without causing any gross structural changes in the optic disc. It has no effect on pupillary reaction as well.

KEY WORDS: Pentoxifylline, optic neuropathy, optic atrophy

INTRODUCTION: Optic atrophy is the end result of various neuropathies. Optic atrophy, irrespective of its etiology, if once sets in, is an untreatable and irreversible phenomenon. Various neuropathies which lead to optic atrophy are glaucoma, ischemic neuropathies (e.g. AION), toxic neuritis (e.g. methyl alcohol, ethambutol), infections (e.g. Tubercular Meningitis), traumatic, and compressive lesions (e.g. aneurysms, Paget's disease, tumours). 
Pentoxifylline is a phosphodiesterase inhibitor with rheological action. [1] It decreases viscosity of the whole blood which results in improved microcirculation. [2] Due to its phosphodiesterase inhibition effect, cyclic adenosine monophosphate (cAMP) levels increase in erythrocytes, endothelium, and surrounding tissues. [3]

It also has immunomodulatory properties which results in vascular endothelial stabilization and autoimmune inhibition, [4]. It decreases peripheral nerve injury by preventing free radical production by neutrophil inhibition and decreasing the levels of cytokines, malondialdehyde and myeloperoxidase. [5]

Pentoxifylline had been used in several studies to restore the normal function of the vasavasorum. [6, 7]

It also has important role in microcirculation regulation and intravascular cell dynamics. [5] Pentoxifylline is also known to increase whole blood filtration rate and deformability of erythrocytes [2] and polymorphonuclear leucocytes in the tissues. [8]

The present study was conducted to assess the role of pentoxifylline in improvement of visual acuity in cases of optic atrophy of recent onset due to various neuropathies.

MATERIAL AND METHOD: A double-blind randomized control study was conducted. Thirty two patients diagnosed as cases of optic atrophy of less than one year duration were selected for the study. Patients were assigned numbers from 1-32. Fifteen cases were randomly selected for study by lottery system. Out of 30 eyes of 15 cases in treatment group, 22 eyes had optic atrophy. Out of 34 eyes of 17 controls, 20 eyes had optic atrophy. Age of the patients, included in the study ranged from 6 years to 75 years. Treatment group was given oral pentoxifylline for minimum period of 6 months. $16-18 \mathrm{mg} / \mathrm{kg}$ body weight of oral pentoxifylline was administered in two equal divided doses. Controls were given placebo for the same duration. All patients with glaucomatous optic atrophy, (either cases or controls) were given anti-glaucoma medications along with pentoxifylline or placebo respectively. Remaining patients with other causes of optic atrophy were kept only on either pentoxifylline or placebo; according to their groups per se. Best corrected visual acuity (BCVA) was assessed regularly at one, three and 6 months with Snellen's visual acuity charts and converted into logarithmic units for statistical analysis. Pupillary reaction esp. relative afferent papillary defect (RAPD) and fundus to assess optic disc changes were also observed in each visit. Statistical analysis was done with SPSS statistics version 19.0.0(SPSS Inc. IBM). Wilcoxon signed rank test, Mann-Whitney test and Hodges-Lehman test (for CI calculation) were used for data analysis. Visual acuity was assessed by a single optometrist (who was blind to the study) in the same dark room with same Snellens' visual acuity chart in each and every visit of all patients.

RESULTS: In both groups majority of the patients ( 9 eyes, $40.91 \%$ in Treatment Group and 8 eyes, $40 \%$ in Control Group) had pre-treatment best corrected visual acuity (BCVA) >20/500 (Chart 1). In Treatment Group, 03 eyes had pre-treatment visual acuity of light perception (PL), which at the end of 6 months attained BCVA of 20/80,20/200, and finger counting at 2 feet respectively. 4 eyes with pre-treatment BCVA of no light perception (NPL), in the same group, showed no improvement after 6 months of therapy. There was no improvement in 2 eyes afflicted with retinitis pigmentosa included in treatment group. 
Among the rest of the patients, in Treatment group pre-treatment and 6 month post-treatment median BCVA were $1.35 \pm 0.44$ and $0.75 \pm 0.45$ respectively ( $\mathrm{p}=0.002, \mathrm{CI}=-0.9$ to -0.25 , Wilcoxonsigned rank test, Hodges-Lehman test) while in Control Group pre-treatment and post treatment median BCVA was $1.32 \pm 0.42$ and $1.31 \pm 0.42$ respectively ( $\mathrm{p}=0.157, \mathrm{CI}=-0.5$ to 0.0 , Wilcoxonsigned rank test, Hodges-Lehman test). There was significant improvement in visual acuity in Treatment group as compared to Control group. (Pre-treatment $\mathrm{p}=0.889, \mathrm{CI}=-0.2$ to 0.4 ; posttreatment $\mathrm{p}=0.002, \mathrm{CI}=-0.9$ to -0.2 , Mann-Whitney U test, Hodges-Lehman test)

In Treatment Group significant improvement was observed in all patients where presenting BCVA was PL+ or more except in retinitis pigmentosa (Table 1,2). Patients with no perception of light showed no improvement.

Pupillary reaction was observed in every follow-up and fundus examination was also done to assess optic disc changes. There was no effect of treatment on pupillary reaction (RAPD) and fundus pictures (optic disc status) in either of the groups.

None of our patients complained of any side effect of the drug.

DISCUSSION: Prospective double-blind randomized controlled study was conducted to evaluate effect of pentoxifylline on cases of optic neuropathy. Best corrected visual acuity (BCVA), changes in pupillary reaction, specifically relative afferent papillary defect (RAPD), as well as optic disc changes were observed. Mean improvement in BCVA was significant in treatment group $(\mathrm{p}=0.001)$ while in the control group visual acuity did not improve significantly. ( $p=0.157)$ (Chart2).

Previous studies have shown role of pentoxifylline in partial normalization of baseline metabolism in cases of non-arteritic ischemic optic neuropathy (NAION). [9] and augmentation of axon regeneration in experimental nerve injury. [10]

Based on the above studies we hypothesized that pentoxifylline may be helpful in optic neuropathy. Encouraging results were obtained when patients were treated with pentoxifylline 16$18 \mathrm{mg} / \mathrm{kg}$ body weight/day divided in two equal doses for at least 6 months. Statistically significant improvement was obtained between treatment and control group $(p=0.002)$ (Chart 2).

In our experience improvement in BCVA was obtained when pentoxifylline was continued for 6 months or longer. Shorter the duration of optic neuropathy better was the result. In our study all but 6 patients showed visual improvement with pentoxifylline. Two each out of these six non responsive cases were due to retinitis pigmentosa and glaucoma and one each due to central retinal artery occlusion and tubercular meningitis. 4 out these 6 non responsive cases had BCVA of NPL.

Reduced ocular blood flow has been implicated as one of the causative factors for optic atrophy in open angle glaucoma patients [11]. Improvement in microcirculation of optic nerve could have been responsible for improvement in visual acuity in such patients.

Improvement in visual outcome in cases of optic atrophy due tubercular meningitis, optic neuritis, NAION and Ethambutol toxicity could be due to immunomodulatory effect, prevention of free radical production as well as improvement in microcirculation

However there was no change in fundus picture of optic nerve and RAPD.

CONCLUSION: Pentoxifylline causes improvement in visual acuity in cases of optic atrophy of shorter duration. Optic atrophy due to vascular insufficiency or inflammation showed better results. Patients with no perception of light showed no improvement. In spite of positive results, 
further studies with larger cohorts and longer duration are required to confirm its role in regaining of visual acuity and its effect on other parameters of vision.

\section{REFERENCES:}

1. Sebag J, Tang M, Brown S, et al. Effects of pentoxifylline on choriodal blood flow in nonproliferative diabetic retinopathy. Angiology 1994;45: 429-33.

2. Katzung BG, Chaterjee K. Vasodilators and the treatment of angina pectoris. In, Katzung BG, Chaterjee K (ed). Basic and Clinical Pharmacology.11th edition. New Delhi, Mc Graw Hills, 2009;205.

3. Ward A, Clissold SP. Pentoxifylline. A review of its pharmacodynamic and pharmacokinetic properties, and its therapeutic efficacy. Drugs 1987; 34:50-97.

4. Constantinescu CS, Hilliard B, Lavi E, et al. Suppression of experimental autoimmune neuritis by phosphodiesterase inhibitor Pentoxifylline. J Neurol Sci1996;143:14-18

5. Savas K, Aras T, Cakmak M, et al. Pentoxifylline inhibits overflow and reduces intestinal reperfusion injury. J Pediatr Surg 1997;32:905-10

6. Inoue A, Koh CS, Tsukada N, Yanagisawa N. Allergic granulomatous angiitis and peripheral nerve lesion. Intern Med 1992; 31:989-93.

7. Eun BL, Liu XH, Barks JD. Pentoxifylline attenuates hypoxic-ischemic brain injury in immature rats. Pediatr Res 2000;47:73-78

8. Armstrong MJ, Needham D, Hatchell DL, et al. Effect of Pentoxifylline on the flow of polymorphonuclear leukocytes through a model capillary. Angiology 1990;41:253-62

9. Bose S, Mok AC, Fallon JH, Potkin SG. Three-month change in cerebral glucose metabolism in patients with non-arteritic ischemic optic neuropathy. Graefe's Archive For Clinical And Experimental Ophthalmology.2006;244:1052-55

10. Baykal, Boz H, Baytan KK. The Effects of Pentoxifylline in Experimental Nerve Injury. Turk J Med Sci .2002;32:207-10

11. Garhöfer G, Fuchsjäger-Mayrl G, Vass C, Pemp B, Hommer A, Schmetterer L. Retrobulbar blood flow velocities in open angle glaucoma and their association with mean arterial blood pressure. Invest Ophthalmol Vis Sci. 2010;51:6652-57 
Table 1: Distribution and effect of treatment on patients with PL or NPL in cases and control group

\begin{tabular}{|c|c|c|c|c|}
\hline \multirow{2}{*}{$\begin{array}{c}\text { No. of eyes/ } \\
\text { Patients }\end{array}$} & \multicolumn{2}{|c|}{ Cases } & \multicolumn{2}{c|}{ Controls } \\
\cline { 2 - 5 } & $\begin{array}{c}\text { Pre- } \\
\text { treatment }\end{array}$ & At 6 month & Pre-treatment & At 6 month \\
\hline 1 & PL & $20 / 80$ & NPL & NPL \\
\hline 2 & PL & $20 / 200$ & PL & PL \\
\hline 3 & NPL & NPL & NPL & NPL \\
\hline 4 & NPL & NPL & NPL & NPL \\
\hline 5 & NPL & NPL & NPL & NPL \\
\hline 6 & NPL & NPL & PL & PL \\
\hline 7 & PL & CF $2 \mathrm{ft}$ & NPL & NPL \\
\hline
\end{tabular}

$\mathrm{PL}=$ Perception of light, NPL= No perception of light, $\mathrm{CF}=$ finger counting

Table 2: Comparison of pre-treatment and post treatment BCVA in cases (group I) on pentoxifylline

\begin{tabular}{|c|c|c|c|c|c|c|}
\hline \multirow{2}{*}{$\begin{array}{l}\text { No. of eyes \& } \\
\text { etiology of } \\
\text { optic atrophy }\end{array}$} & \multirow{2}{*}{$\begin{array}{l}\text { Snellen } \\
\text { Pretreatme } \\
\text { nt }\end{array}$} & \multicolumn{2}{|c|}{$\begin{array}{l}\text { Snellen (post } \\
\text { treatment) }\end{array}$} & \multirow{2}{*}{$\begin{array}{l}\text { Logmar } \\
\text { Pretreatment }\end{array}$} & \multicolumn{2}{|c|}{$\begin{array}{l}\text { Logmar (post } \\
\text { treatment) }\end{array}$} \\
\hline & & $\begin{array}{l}3 \\
\text { months }\end{array}$ & $\begin{array}{l}6 \\
\text { months }\end{array}$ & & $\begin{array}{l}3 \\
\text { months }\end{array}$ & $\begin{array}{l}6 \\
\text { months }\end{array}$ \\
\hline 1 ( TBM) & PL & $20 / 200$ & $20 / 80$ & & & \\
\hline $2(\mathrm{TBM})$ & PL & $\begin{array}{l}\text { FC at } 2 \\
\text { feet }\end{array}$ & $20 / 200$ & & & \\
\hline 3 ( TBM) & NPL & NPL & NPL & & & \\
\hline 4 (TBM) & $20 / 1200$ & $20 / 40$ & $20 / 30$ & 1.8 & 0.3 & 0.2 \\
\hline $\begin{array}{l}5 \text { (Ethambutol } \\
\text { toxicity) }\end{array}$ & $20 / 200$ & $20 / 120$ & $20 / 40$ & 1 & 0.8 & 0.3 \\
\hline $\begin{array}{l}6 \text { (Ethambutol } \\
\text { toxicity) }\end{array}$ & $20 / 240$ & $20 / 200$ & $20 / 200$ & 1.1 & 1 & 1 \\
\hline 7 (Glaucoma) & NPL & NPL & NPL & & & \\
\hline 8 (Glaucoma) & NPL & NPL & NPL & & & \\
\hline 9 (Glaucoma) & $20 / 200$ & $20 / 120$ & $20 / 40$ & 1 & 0.8 & 0.3 \\
\hline 10(Glaucoma) & $20 / 2000$ & $20 / 1500$ & $20 / 1500$ & 2 & 1.9 & 1.9 \\
\hline 11(Glaucoma) & $20 / 240$ & $20 / 200$ & $20 / 120$ & 1.1 & 1 & 0.8 \\
\hline 12(Glaucoma) & $20 / 1500$ & $20 / 400$ & $20 / 120$ & 1.9 & 1.3 & 0.8 \\
\hline 13(Glaucoma) & PL & PL & $\mathrm{FC}$ at 2 & & & \\
\hline
\end{tabular}




\section{ORIGINAL ARTICLE}

\begin{tabular}{|l|l|l|l|l|l|l|}
\hline & & & feet & & & \\
\hline $14(\mathrm{ON})$ & $20 / 1200$ & $20 / 200$ & $20 / 80$ & 1.8 & 1 & 0.6 \\
\hline $15(\mathrm{ON})$ & $20 / 80$ & $20 / 80$ & $20 / 40$ & 0.6 & 0.6 & 0.3 \\
\hline $16(\mathrm{CRAO})$ & NPL & NPL & NPL & & & \\
\hline $17($ NAION) & $20 / 200$ & $20 / 200$ & $20 / 80$ & 1 & 1 & 0.6 \\
\hline $18($ NAION) & $20 / 1200$ & $20 / 200$ & $20 / 120$ & 1.8 & 1 & 0.8 \\
\hline $19($ NAION) & $20 / 1200$ & $20 / 120$ & $20 / 80$ & 1.8 & 0.8 & 0.6 \\
\hline $20($ NAION) & $20 / 200$ & $20 / 120$ & $20 / 80$ & 1 & 0.8 & 0.6 \\
\hline $21(\mathrm{R})$ & $20 / 400$ & $20 / 400$ & $20 / 400$ & & & \\
\hline $22(\mathrm{R} P)$ & $20 / 240$ & $20 / 240$ & $20 / 240$ & & & \\
\hline
\end{tabular}

$\mathrm{TBM}=$ Tubercular meningitis, $\mathrm{ON}=$ Optic neuritis, NAION= Non arteritic ischemic Optic neuropathy, $\mathrm{CRAO}=$ Central retinal artery occlusion, $\mathrm{RP}=$ Retinitis pigmentosa

PL= Perception of light, NPL= No perception of light

Chart 1: BCVA distribution in cases and control

\section{BCVA distribution in Groups}

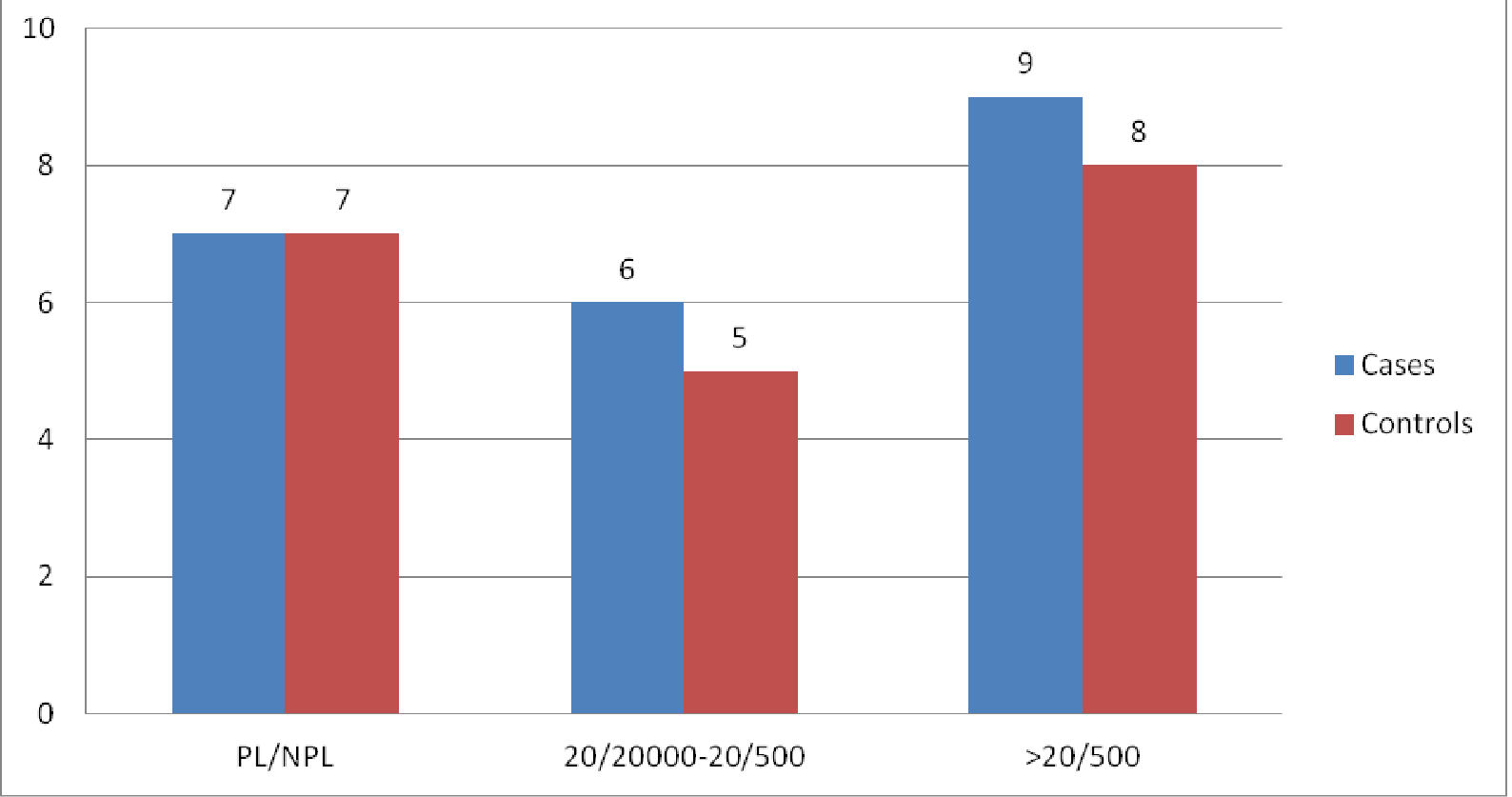




\section{ORIGINAL ARTICLE}

Chart 2: Comparision of pre treatment and post treatment BCVA in cases and control groups after administration of pentoxyphilline and placebo respectively

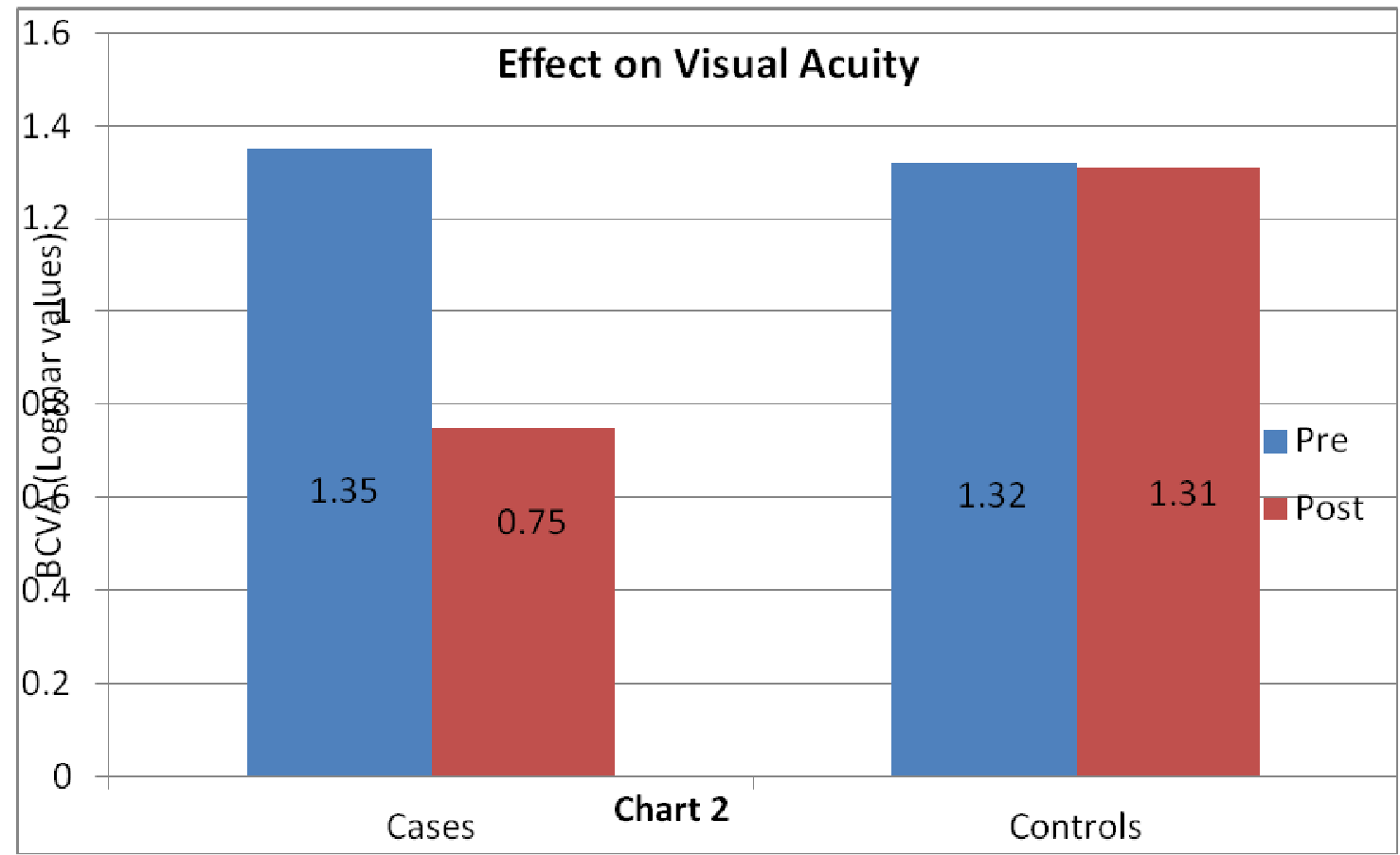

